\title{
El impacto de la romanización augustea en la cuenca del Duero
}

\author{
Manuel SAlinAS DE FRÍAS \\ Universidad de Salamanca \\ vafio@usal.es
}

\begin{abstract}
RESUMEN
A pesar de la decisiva importancia del reinado de Augusto, ya que fue él precisamente quien sometió los territorios situados al norte del Duero, es difícil hacer un balance del impacto de la romanización bajo su reinado. Básicamente, dicha información está constituida por tres clases de datos: las fuentes literarias relativas a la guerra de Augusto contra los astures y los cántabros; las fuentes arqueológicas que documentan, principalmente, la presencia de campamentos militares romanos o los momentos iniciales de un desarrollo urbano cuya interpretación sigue planteando numerosos problemas; $y$, finalmente, unas muy escasas fuentes epigráficas que atestiguan la reorganización administrativa del territorio (termini augustales, termini pratorum, etc.), o bien aspectos concretos de las comunidades indígenas que son difíciles de relacionar con los acontecimientos generales del Imperio o del gobierno de Augusto en la península Ibérica.
\end{abstract}

Palabras clave: Augusto. Romanización. Cuenca del Duero. Hispania. Epigrafía latina. Sociedad hispano-romana.

\section{The Impact of the Augustan Romanization in the Basin of the Douro River}

\begin{abstract}
Despite the critical importance of the reign of Augustus for this region, because he was who subjected territories just north of the Douro, it is difficult to balance the impact of Romanization under his reign. Basically, the information is made up of three types of data: the literary sources relating to the War of Augusto against Cantabrians and Asturians; archaeological sources documenting mainly the presence of Roman military camps or the initial stages of urban development whose interpretation still poses numerous problems; and finally very few epigraphic sources attesting the administrative reorganization of the territory (termini augustales, termini pratorum), or specific aspects of the indigenous communities that are difficult to relate to the general events of the empire or of the Augustus' government in the Iberian peninsula.
\end{abstract}

Key Words: Augustus. Romanization. Douro basin. Hispania. Latin epigraphy. Hispano-Roman society.

Sumario: 1. Las fuentes literarias y el valle del Duero: una entidad geográfica tardíamente percibida. 2. Las fuentes arqueológicas: organización territorial y presencia militar. 3. Las fuentes epigráficas: reorganización del territorio y una limitada promoción jurídica. 
La comunicación que presentamos corresponde a un proyecto de investigación cuyo título es "Comunidades cívicas en la cuenca del Duero, de Augusto a Vespasiano" y cuyo objetivo es trazar un panorama general de la romanización en dicha área geográfica utilizando como vector principal de estudio las formas de organización urbana representadas por Roma. ${ }^{1}$ A pesar de la decisiva importancia del reinado de Augusto para la romanización de esta región, ya que fue él precisamente quien acometió la conquista de los territorios situados al norte del Duero, pertenecientes a los astures y los cántabros, culminando con ello la conquista de Hispania, es difícil hacer un balance de su actuación y del impacto de la romanización bajo su reinado debido a la escasez de información y a lo heterogéneo de la misma, lo que impide llegar todavía a una síntesis satisfactoria.

Básicamente, dicha información está constituida por tres clases de datos:

- Las fuentes literarias relativas a la guerra de Augusto contra los astures y los cántabros.

- Las fuentes arqueológicas que documentan, principalmente, la presencia de campamentos militares romanos o los momentos iniciales de un desarrollo urbano cuya interpretación sigue planteando numerosos problemas.

- Y, finalmente, unas muy escasas fuentes epigráficas que atestiguan la reorganización administrativa del territorio (termini augustales, termini pratorum, etc.), o bien aspectos concretos de las comunidades indígenas peregrinas que son difíciles de relacionar con los acontecimientos generales del Imperio o del gobierno de Augusto en la península Ibérica.

\section{Las fuentes literarias y el valle del Duero: una entidad geográfica tardíamente percibida}

La cuenca del Duero no ha sido percibida como una entidad geográfica propia sino hasta fecha muy tardía y, para esa percepción, la actuación de Augusto en Hispania ha jugado un papel fundamental. Suele atribuirse a la diferente naturaleza de las fuentes literarias relativas al periodo republicano y las relativas al periodo imperial el hecho de que, antes del primer emperador, ningún escritor antiguo haya apreciado la unidad del curso del río y las tierras por las que éste discurre. Las primeras estarían más interesadas en la narración de las guerras de conquista y, por tanto, en la descripción de las unidades étnicas contra las que luchaban los romanos; mientras que las segundas estarían interesadas, por el contrario, en la descripción del territorio y de sus recursos naturales, proporcionándonos, de esta manera, una comprensión nueva de las unidades fisiográficas. ${ }^{2}$

Sin embargo, puede comprobarse que dicha divergencia no es fruto de la distinta naturaleza de las fuentes literarias, sino de la percepción histórica de los romanos. La conquista de la Meseta central se hizo partiendo de dos provincias diferentes y esta

1 Proyecto de $\mathrm{i}+\mathrm{d}+\mathrm{i}$ : HAR2011-27719.

2 Nicolet 1988, Prontera 1990, Cruz et alit 2007. 
duplicidad impidió ver la cuenca del Duero como una unidad geográfica. Cuando en el año 179 a.C. Sempronio Graco y Postumio Albino acordaron atacar a los celtíberos en una maniobra envolvente partiendo cada uno desde su respectiva provincia, decidieron coincidir in ultima Celtiberia, es decir en el valle oriental del Duero, ${ }^{3}$ omitiendo sin embargo Livio la mención del río. Décimo Bruto, durante su campaña contra los lusitanos en el año 136 a.C., fortificó ciudades en la desembocadura de algunos ríos de la fachada atlántica, como Moron y Olisipo ${ }^{4}$ evidentemente como bases de penetración hacia el interior. Apiano cita como jalones de su campaña los ríos Duero, Lethes y Nimis (Minius?), ${ }^{5}$ pero no se refiere en absoluto al interior de sus valles. Poco más tarde, durante la campaña de Escipión contra Numancia, el mismo Apiano ${ }^{6}$ refiere cómo cerró el curso del Duero a la navegación para impedir que los numantinos recibieran víveres y refuerzos de los vacceos, pero el horizonte geográfico de su narración no va más hacia el oeste. Es decir, tenemos una misma fuente, Apiano, o mejor dicho sus fuentes (Polibio y la analística romana esencialmente) y unos mismos hechos históricos, ubicados unos en el alto Duero y otros en la desembocadura del mismo río, pero, sin embargo, el autor clásico no percibe la unidad geográfica.

No es sino hasta Estrabón, contemporáneo de Augusto, cuando encontramos una primera descripción del Duero (III 3.4), de lejanas fuentes, que pasa junto a Numancia y otras muchas ciudades de los celtíberos y vacceos, y desemboca en la costa occidental, pudiendo remontarlo los navíos grandes unos 800 estadios, es decir, unos $150 \mathrm{~km}$. Esta descripción de Estrabón, sin embargo, no supera apenas la percepción de Apiano, y, de hecho, no cita en relación con el río los pueblos situados al occidente de los vacceos. Hay que esperar a Plinio para hallar una expresión coherente del espacio geográfico (NH. IV 34.112): el río Duero, de los más grandes de Hispania, nace entre los pelendones y pasa cerca de Numancia, corre luego por entre los arévacos y los vacceos y separa de Asturia a los vettones y de Lusitania a los galaicos y, allí mismo, a los túrdulos de los brácaros. En la descripción que hace Plinio, el río, que sirve de frontera, es simultáneamente, también, bisagra de unión de las comunidades y del territorio que se organiza en torno a él ${ }^{7}$ pero, como vemos, no es sino hasta después de Augusto, precisamente a consecuencia de la conquista de los cántabros y astures, cuando los romanos cobran conciencia de la unidad del espacio geográfico. Podríamos decir que, en este caso, la política ha creado la geografía.

Por su posición geográfica, la cuenca del Duero jugó un papel esencial en la estrategia de las guerras contra los cántabros y astures con las que Augusto completó la conquista romana de la península Ibérica. De acuerdo con las fuentes literarias, ${ }^{8}$ el ejército romano penetró con tres columnas en el territorio cántabro-astur partiendo de bases establecidas en la línea del río, mientras que la flota romana, procedente de Aquitania, desembarcaba en la costa cantábrica. A pesar de esta importancia, los tes-

3 Liv., 40.47.

4 Str., III 3.1.

5 App., Ib. 72.

6 App., Ib. 91.

7 Roddaz, 2007; Traina 2007.

8 Floro 2.33.48. 
timonios augusteos en esta región son muy escasos y, por tanto, es difícil evaluar el mayor o menor progreso de la romanización en ella durante su época.

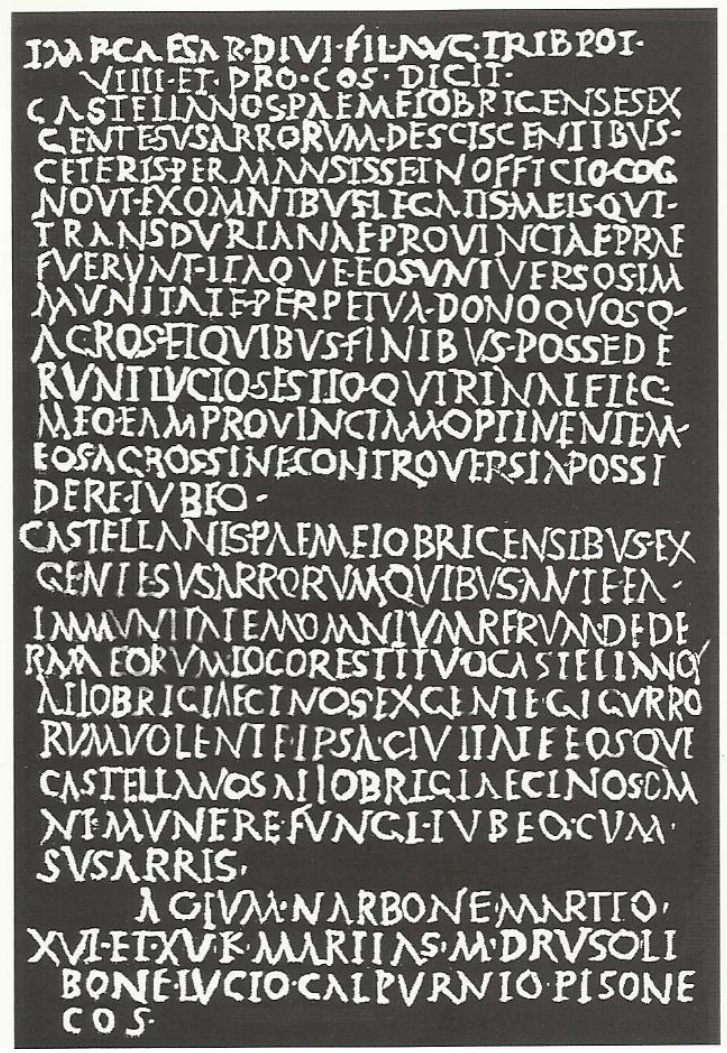

Fig. 1. Edicto de Augusto del año 15 a.C. o "Bronce de El Bierzo". Facsímil según GrauHoyas 2001.

Entre el año 29 y el 15 a.C. toda la cuenca del Duero fue una zona de guerra. Un testimonio importantísimo en este sentido es el denominado bronce de El Bierzo, un edicto dado por el emperador en Narbona en el año 15 a.C. acerca de dos comunidades indígenas, los Susarri y los Gigurri (Fig. 1). La mención en él de una Transduriana provincia tiene que ver con dicha situación de guerra, a la que el documento se refiere indirectamente cuando dice (lin. 4-5): (...) castellanos Paemeiobrigenses ex/ gente Susarrorum desciscentibus/ ceteris permansisse in officio (...). Las interpretaciones que se han hecho acerca de la naturaleza jurídica de dicha provincia son casi tantas como los historiadores que se han referido a ella ${ }^{9}$ pero, puesto que no es el objeto ahora de nuestra investigación, no vamos a detenernos en ello. Por mi parte creo,

9 Costabile - Licandro 2000; Sánchez Palencia - Mangas 2000; Grau - Hoyas 2001; las revisiones más recientes son las de MARTín 2008 y LóPEZ-BARJA 2010, que inciden en ideas ya señaladas por la investigación anterior. 
como ya expuse en otro lugar, ${ }^{10}$ que dicha provincia debió de consistir originalmente en el mandato dado al emperador por el Senado y el pueblo para hacer la guerra contra los pueblos del norte, dentro del sentido personal de la provincia en el vocabulario político de la República romana, que no había desaparecido aún en época de César.

Ahora bien, dicho mandato personal cobró enseguida un sentido territorial como la referencia misma a un accidente geográfico, el río Duero, da a entender. El problema estriba en saber cuál era la superficie geográfica comprendida dentro de la provincia, acerca de lo cual tampoco hay unanimidad entre los historiadores. En mi opinión, dicha superficie era el territorio de los astures, es decir, grosso modo, la tierra situada en el interfluvio del Duero y el Esla (Astura), en dirección hacia la cordillera y la costa cantábrica situada al norte de la misma. Las razones de esta interpretación son varias. En primer lugar, el hecho de que la topografía concreta de la guerra se desarrolla casi siempre en territorio astur, siendo Lancia la ciudad de los astures en torno a la cual se producen los principales combates. ${ }^{11}$ Otros escenarios, como la ciudad de Bergida, que se puede identificar con Bergidum Flavium (Villafranca de El Bierzo), ${ }^{12}$ Brigaecium, identificable con algún lugar próximo a Benavente o a Fuentes de Ropel, en la provincia de Zamora, ${ }^{13}$ o el mons Medulius, verosímilmente identificable con Las Médulas, ${ }^{14}$ se sitúan dentro de este territorio; y otros, como el mons Vindius en el que los cántabros resistieron hasta la derrota definitiva, ${ }^{15}$ sencillamente no sabemos dónde están; y pueden corresponder al sector occidental de los picos de Europa, ya que los cántabros antiguos penetraban en la zona oriental de la actual Asturias, siendo el curso del Sella la línea divisoria entre cántabros y astures. ${ }^{16}$ Otro argumento, complementario del primero, es la ubicación de las legiones que quedaron de vigilancia en el norte hispano después de la guerra. Dos legiones, la VI y la X, se ubicaron en territorio de los astures, mientras que solamente una, la IV Macedónica, en el de los cántabros. La situación de esta última legión en Herrera de Pisuerga y el hecho de que Pisoraca se convirtiera en una mansio de la via in Aquitaniam per Cantabriam, da a entender que su función estaba más relacionada con la vigilancia de dicha vía que con otras eventuales funciones de represión de las comunidades cántabras. No creemos que la posición de estas unidades militares tenga nada que ver con la existencia de ninguna clase de limes establecido frente a los pueblos del norte, ${ }^{17}$ ni que dicho limes perdurara hasta el Bajo Imperio, a semejanza del limes renano o danubiano. ${ }^{18}$ No solamente la estructura física de ambos es diferente a lo que encontramos en Hispania ${ }^{19}$ sino que hay, además, una diferencia fundamental: mientras que en el Rin

10 Salinas 2001.

11 Dión Casio, 53.25; Floro, 2.33.57; Orosio, 6.21. Sobre el carácter ideológico de las fuentes en su presentación de los cántabros y astures, SALINAs 1998.

12 Floro, 2.33.49.

13 Floro, 2.33.55.

14 Floro, 2.33.50.

15 Floro, 2.33.49.

16 BARBERo - Vigil 1974, 164-166.

17 Morillo 2007a, 91; la expresión "limes sin frontera" nos parece poco comprensible.

18 BARbero - Vigil 1974, 13-21; ArCE 1982, 67-69.

19 D'AREMBERG - SAGLio III, col. 1255 y ss, sv. Limes imperii; KANDLER 1989. 
o el Danubio los campamentos romanos estaban frente al territorio bárbaro independiente, en el caso de Hispania las guarniciones militares estaban situadas dentro de los cántabros y astures.

Es posible, en fin, que la Transduriana provincia fuese en líneas generales aquella porción de territorio que, bien entre el 14 y el 12 a.C. al crearse las tres nuevas provincias, o entre el 7 y el 2 a.C., fue transferida de la Lusitania a la Tarraconense según consta en las fuentes literarias.

\section{Las fuentes arqueológicas: organización territorial y presencia militar}

Sobre este territorio, el valle del Duero, se sitúan diferentes campamentos militares y dispositivos que tienen que ver con la guerra contra los cántabros y astures, cuyo conocimiento se ha incrementado notablemente en las últimas décadas, principalmente gracias a las intervenciones arqueológicas (Fig. 2). Al periodo que va del 29 a.C. al 19 a.C., es decir al periodo estricto de la guerra, pertenecen una serie de campamentos o recintos militares situados en la vertiente meridional de la cordillera Cantábrica, controlando los pasos naturales desde el interior hacia la costa. Son el conjunto de campamentos que se disponen en torno a un importante castro indígena, denominado La Espina del Gallego (Cantabria), configurando una estructura de asedio comparable a la de Alesia en las Galias. Son los campamentos de Cildá, El Cantón y Campo de las Cercas. Más hacia el sur, marcando el camino de penetración por la cordillera, se sitúan los campamentos de El Cincho (Población de Yuso, Cantabria), La Muela (Sotoscueva, Burgos), El Castillejo (Pomar de Valdivia, Palencia) y, hacia el oeste, La Carisa (Lena, Asturias). ${ }^{20}$

El final de la guerra y la marcha de cuatro de las siete legiones que habían participado en ella a otros lugares del Imperio abren un segundo periodo que se extiende desde el 19 a.C. al 15 d.C. En este periodo se sientan las bases de una política militar de ocupación del territorio a largo plazo que se apoya sobre tres legiones: la IIII Macedonica, acuartelada en Herrera de Pisuerga; la VI Victrix, establecida en León; y la $X$ Gemina, acantonada en Astorga y en Rosinos de Vidriales. Estos tres lugares son los primeros campamentos legionarios permanentes constatados arqueológicamente. ${ }^{21}$ Ninguno de ellos presenta restos pertenecientes al periodo estricto de la guerra y constituyen por tanto la expresión de la nueva política militar que Augusto desarrolla frente a las poblaciones septentrionales de Hispania. Algunos de estos campamentos, como León o Astorga, se encuentran bajo ciudades actuales, lo que dificulta su conocimiento arqueológico. Por otra parte, la técnica de castramentación en esta fecha temprana no se halla completamente desarrollada, de manera que la identificación de estructuras constructivas propias de un asentamiento militar a veces resulta muy difícil. ${ }^{22}$

20 Morillo 2007a, 101-103; MORILLO ET ALII 2008, 111-120.

21 Morillo 2007a, 103; para lo que sigue, 103-109.

22 Morillo, 2007a, 98; ID. 2008; REDDÉ 2008. 


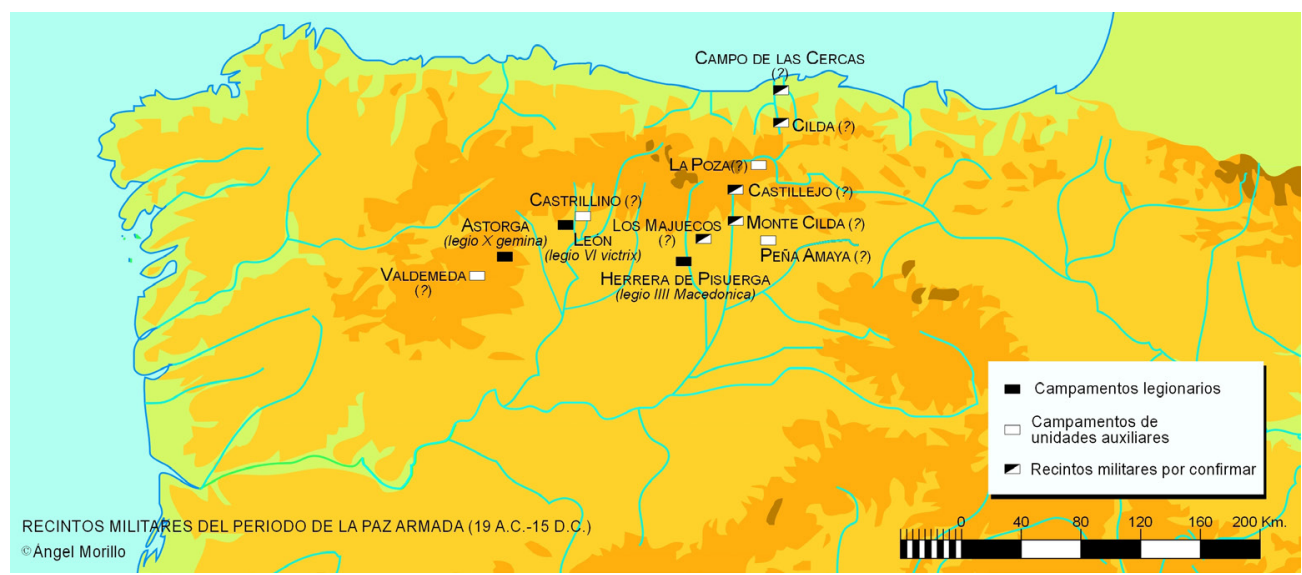

Fig. 2. Establecimientos militares del periodo 19 a.C. - 15 d. C., según A. Morillo.

El origen del campamento de Herrera de Pisuerga ${ }^{23}$ tiene lugar hacia los años 20/15 a.C., durante las campañas de Agripa, o unos años antes. Se sitúa junto al río Pisuerga, la principal vía de penetración desde la Meseta hacia el interior de la cordillera y el mar, y albergó a la legio IIII Macedonica hasta su traslado a Mogontiacum (Mainz) en el año 39 a.C., en época de Tiberio.

Las excavaciones y sondeos arqueológicos realizados en Astorga $^{24}$ han permitido identificar una fase militar inicial anterior al cambio de Era, hacia los años 15/10 a.C., y las evidencias epigráficas han permitido identificar a la legio X Gemina como la unidad que ocupaba el campamento. Hacia los años 15/20 d.C., es decir, ya con Tiberio se produce una gran remodelación urbanística con potentes niveles de relleno en toda la superficie ocupada posteriormente por la ciudad. En este momento la legio $X$ se trasladaría a un nuevo campamento ubicado en Rosinos de Vidriales (Zamora), unos $50 \mathrm{~km}$ más al sur. El momento final de este nuevo campamento se situaría en el año 63 d.C., en el que legión fue trasladada a Carnuntum.

Finalmente, las excavaciones arqueológicas en la ciudad de León ${ }^{25}$ han permitido identificar dos recintos campamentales anteriores al establecimiento de la legio VII gemina, a la cual se atribuía el origen de la ciudad. El más antiguo de ellos es un campamento de época augustea con un agger con foso de perfil en "V" y terraplén que fueron profundamente transformados hacia los años 15/20 d.C., es decir por las mismas fechas en que Astorga fue remodelada. El campamento augusteo estuvo ocupado por la legio VI Victrix, hasta que esta partió de la península en el año 69 d.C. para acompañar a Galba en su lucha por el poder del Imperio. Estos campamentos legionarios estuvieron acompañados por un número indeterminado de campamentos menores, fuertes, etc., a los cuales se destinaron destacamentos legionarios o unida-

23 Morillo 2007a, 103; NúÑEZ - CURChin 2007, 533-542.

24 Morillo 2007a, 103-105, p. 104 fig. 9; ID. 2007b; NúÑEZ - CURCHIN 2007, 443-451.

25 Morillo 2007a, 105-107; ID. 2007 b. 
des auxiliares. Se han documentado fuertes en Valdemeda (León), Villalazán (Zamora) y Burgo de Osma (Soria). ${ }^{26}$

Tanto las legiones como las tropas auxiliares tuvieron asignados prata para el mantenimiento de sus yeguadas y, en general, como complemento económico de las mismas. A través de la epigrafía conocemos algunos de estos prata, delimitados y separados del territorium de las civitates mediante termini pratorum. En la provincia de León se conocen los termini que delimitaban los prata de la legio X Gemina y la ciudad de Bedunia, en Quintana y Congosto; ${ }^{27}$ así mismo de la cohors IIII Gallorum y Bedunia en Castrocalbón y Santa Colomba de la Vega (León); ${ }^{28}$ y de la cohors IIII Gallorum y los Luggones en Santa Colomba de la Vega, ${ }^{29}$ estos últimos de entre los años 41-54 d.C. En la provincia de Cantabria se conocen los termini que delimitaban los prata de la legio IIII y la ciudad de Iuliobriga, en Valdolea. ${ }^{30}$ En la de Burgos se conocen también los de la legio IIII y la ciudad de Segisamo, en Villasidro, de los años 16 a.C.- 5 d.C. ${ }^{31}$ Es decir, el territorio resultante de esta ocupación militar fue un territorio fragmentado, compartimentado, distinto del territorio de otras zonas de Hispania como la Lusitania, la Bética o la Citerior mediterránea, en el cual los prata militares se incrustaban en el territorium de las civitates, así como las zonas de explotación minera que debieron constituir zonas de saltus publicus. ${ }^{32}$

\section{Las fuentes epigráficas: reorganización del territorio y una limitada promoción jurídica}

Como es conocido, una vez terminada la guerra Augusto procedió a trasladar a los indígenas de las sierras a los valles, donde eran más fácilmente controlables, y a crear distintos núcleos urbanos que, a la vez que servían de puestos de vigilancia, sentaron las bases de la romanización de la región. ${ }^{33}$ La política augustea de fundación de ciudades nos coloca frente a dos problemas: el del estatuto jurídico de las ciudades que de alguna manera incorporan el nombre del emperador en el suyo propio y el de la promoción jurídica de los núcleos urbanos creados entonces o preexistentes (Fig. 3).

\footnotetext{
26 Morillo 2007a, 107.

27 CORTÉS BÁRCENA 2013, nº48.

28 CORTÉs BÁRCENA 2013, nos. 18-21.

29 CORTÉs BÁRCENA 2013, nos. 23-24.

30 CORTÉs BÁRCENA 2013, nos. 29-30.

31 CORTÉS BÁRCENA 2013, nº 47.

32 SASTRE 2001, 95 y ss; ID. 2002, 103-125.

33 Floro 2.33.59-60: ... tum consilio Caesaris, qui fiduciam montibus timens, in quos se recipiebant, castra sua, quia in plano erant, habitare et intolere iussit.
} 


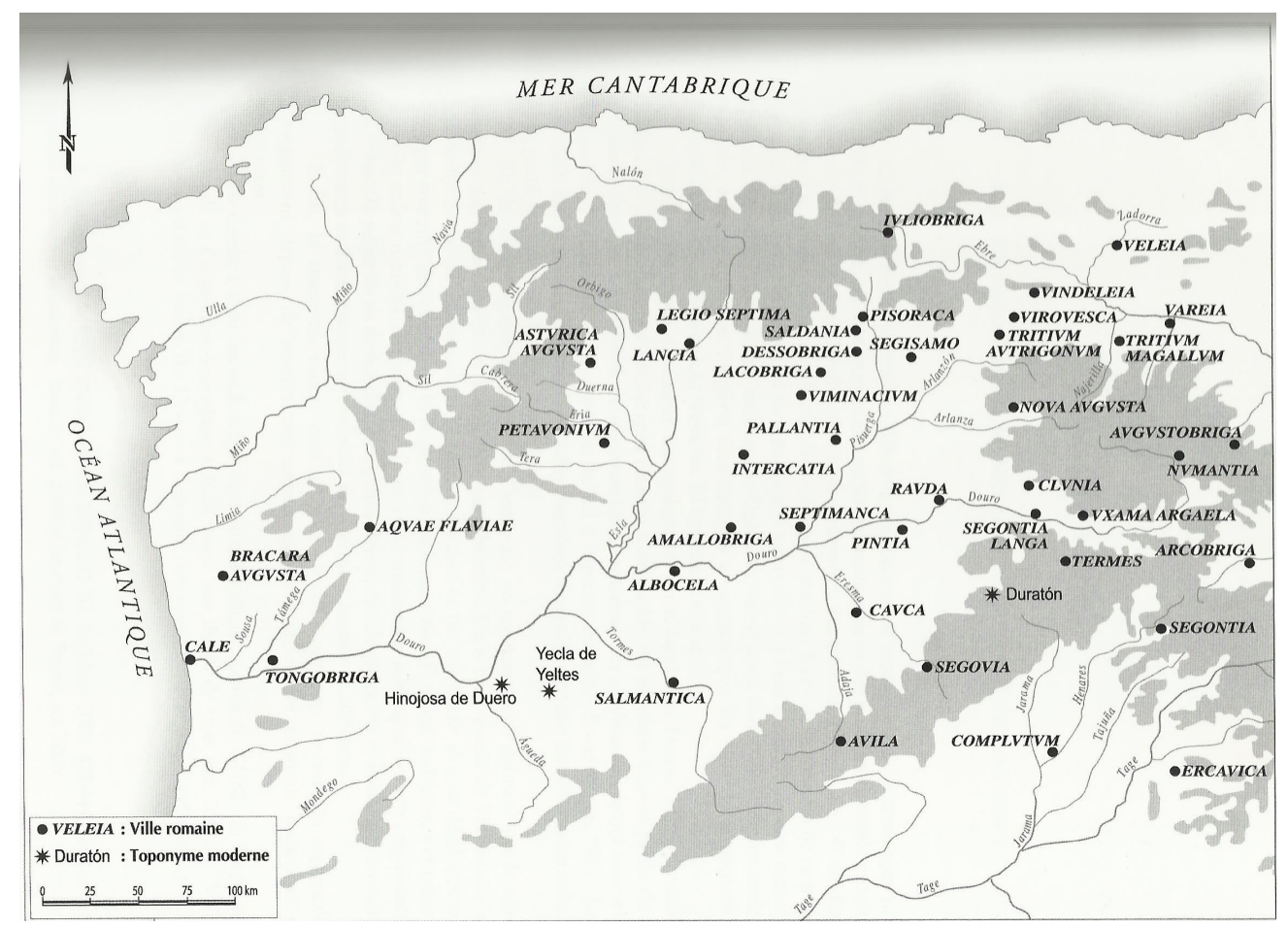

Fig. 3. Ciudades hispanorromanas de la cuenca del Duero, según Navarro Caballero - Palao Vicente 2007.

Las ciudades del valle del Duero que incorporan el nombre del emperador son: Asturica Augusta (Astorga), Augustobriga (Muro de Ágreda), Bracara Augusta (Braga) y Nova Augusta (¿Lara de los Infantes?). Su problemática está relacionada con otra fundación, Iuliobriga (Retortillo), fuera de nuestro marco geográfico. En el siglo II d.C. Bracara tenía decuriones ${ }^{34}$ y sus ciudadanos se inscribían en la tribu Quirina, con lo

cual es factible suponer que se convirtió en municipio en la época flavia, quedando en suspenso la posibilidad enunciada por P. Le Roux de que, desde Augusto, sus habitantes tuvieran el derecho latino. De la misma manera, se ha supuesto que Asturica fuese municipio, dada su condición de capital conventual, pero de momento no hay ningún dato que lo avale con seguridad. ${ }^{35}$ Un caso como el de Augustobriga, con el compuesto céltico - briga, casi excluiría a priori una condición municipal. Por el contrario, la lista de ciudades que, en un momento u otro, parecen haberse convertido en munici-

34 CIL II, 2424.

35 NúÑEZ - CURChIN 2007, 443-451 y 455-465. 
pios es la siguiente: ${ }^{36}$ Clunia, Duratón, Lancia, Lara de los Infantes, ${ }^{37}$ ¿Numancia?, Pallantia, ¿Pisoraca?, Salmantica, Segovia, Termes, Urunia y Uxama Argaela. Tres de ellas, Clunia, Termes y Uxama, parecen haber alcanzado tempranamente la condición municipal pero, por los datos que tenemos, dicha promoción no parece haberse producido durante el reinado de Augusto sino el de su sucesor, Tiberio.

De Clunia se conoce la adscripción de sus ciudadanos a la tribu Galeria, ${ }^{38}$ así como a la Quirina. ${ }^{39}$ La idea de que Clunia se convirtió en municipio en época de Tiberio se debe al hecho de que la ciudad acuñó monedas en época de éste, con cabeza del emperador en el anverso y los nombres de los quattuorviri y aediles en el reverso. ${ }^{40}$ La probable datación de la municipalización de Clunia con Tiberio ha atraído también las cronologías propuestas para la municipalización de Tiermes y Uxama. De Tiermes se conoce su condición municipal en el siglo II d.C. por una tabula de hospitalidad procedente de Peralejo de los Escuderos (Soria) ${ }^{41}$ y se ha supuesto que su promoción se produjera por las mismas fechas que la de Clunia. Sus ciudadanos, lo mismo que los de Uxama, estaban inscritos en la tribu Galeria. ${ }^{42}$ La existencia de una inscripción en Tiermes dedicada a Tiberio podría constituir un argumento adicional para defender la municipalización bajo este emperador. ${ }^{43}$

Además de ello, una inscripción en bronce, de la que sobreviven cuatro fragmentos, hallada en Segovia, documenta la existencia de un pontifex flamen Tiberi Caesaris Augusti, que a continuación desempeñó cargos ecuestres ${ }^{44}$ Es posible que la inscripción, como señalan sus editores, sea contemporánea de este emperador, aunque el hecho de que Tiberio no fuese divinizado a su muerte impide estar seguros de esta circunstancia. En todo caso, más que atestiguar la existencia de un sacerdocio de este tipo en la ciudad arévaca, creemos que se trata de un homenaje a un ecuestre importante cuyas relaciones con la ciudad, que se promocionó a municipio en época flavia, nos son desconocidas.

Estas promociones de ciudades arévacas, en nuestra opinión, están más relacionadas con la romanización del valle del Ebro, que es una zona con la cual los arévacos muestran mayores afinidades culturales, que con las de Meseta central. Esta conexión puede observarse particularmente en el hecho de que Augusto convirtió en municipios a otras ciudades celtibéricas del valle del Ebro, como Turiaso o Bilbilis, pero no a ciudades de la zona central u occidental del Duero (vacceos, astures y vettones). Por otra parte, en la época republicana, el fenómeno monetal muestra afinidades entre

36 NúÑEZ - CURChIN 2007, que no incluyen Urunia (Irueña, en la provincia de Salamanca) cuya condición municipal puede despenderse de una dedicatoria a Septimio Severo hecha por el o(rdo) m(unicipiii) U(runiensis): CIL II, 863; cf. SALINAS - RodRÍGUEZ 2007, 171.

37 ABÁSOLO 2007.

38 CIL II, 2782, 2785 у 2800; ERClu 72 у 79.

39 CIL II, 2798, 2802.

40 Villaronga 1979, 286; Alfaro 1997, 356.

41 BALBín 2006, nº56.

42 CIL II, $2403=5558,5795$.

43 HEP 13, 2003-2004, 655; AE 2004, 789.

44 Santos Yanguas et alit 2005, 144-148, nº66: [T(ito)? Aem]ilio T(iti) f(ilio)/ Mu[mm]io Prisco/ Cor[nel]iano Lepi/ do p[ont]if(ici) flamini/ Tib(erii) C[aes(aris)] Aug(usti) trib(uno) mil(itum)/ [leg(ionis) ....] .../ ¿d(ecreto) [d(ecurionum)?]. 
el valle oriental del Duero, la Celtiberia, y el valle del Ebro; y en cambio diferencias con el centro y occidente de su cuenca. Las ciudades arévacas conocieron el uso de la moneda, mientras que el centro y occidente del río, territorio de vacceos y vettones, no. ${ }^{45}$ El resto de las ciudades, es decir, Duratón, Lancia, Pallantia, Pisoraca, Salmantica, Segovia y Urunia debió de alcanzar el estatuto municipal más tarde y, casi con seguridad, en relación con la municipalización flavia.

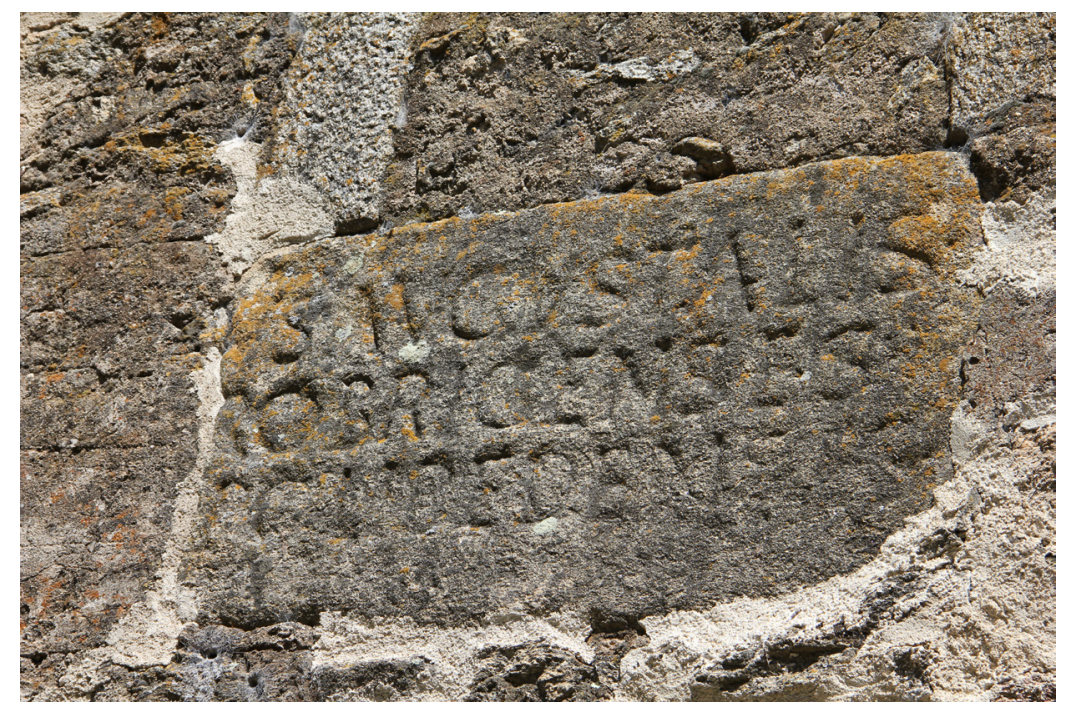

Fig. 4. Terminus augustalis de Traguntía (Salamanca). Foto de M. Salinas y J. J. Palao.

En la parte occidental, no obstante, bajo el gobierno de Augusto hubo una reorganización territorial muy importante, de la que tenemos relativamente abundantes datos. Dicha reorganización se conoce principalmente por algunos termini augustales, así como por algunos miliarios. Tradicionalmente se ha puesto dicha reorganización en relación con la división de las provincias y los cambios de fronteras entre la Citerior y la Lusitania, pero creemos que, por las fechas que aparecen en los termini, ello no es así, ya que dichos termini son casi dos décadas posteriores a la probable fecha de reorganización provincial. Este lapso parece excesivo para una medida que, por sus implicaciones fiscales, no podía demorarse mucho en el tiempo sin perjuicio de la administración. Hay que pensar por lo tanto en otras causas.

Las ciudades cuyos territoria se definieron en dicho momento eran todas civitates stipendiariae. Los termini, algunos de ellos ya conocido por Hübner, son los siguientes: en la provincia de Salamanca los de Ledesma, entre los Bletisamenses, Mirobrigenses y Salmanticenses, del año 5-6 d.C.; ${ }^{46}$ Traguntía, entre los Mirobrigenses y los Polibedenses?, del 4-6 d.C. (Fig. 4); ${ }^{47}$ Ciudad Rodrigo, entre los Mirobrigenses y los

45 BARRANDON 2011.

46 CORTÉS BÁRCENA 2013, n³.

47 CORTÉS BÁRCENA 2013, $\mathrm{n}^{\mathrm{0}} 7$. 
Bletisamenses, del 5-6 d.C.; ${ }^{48}$ otro más de Ciudad Rodrigo, entre los Mirobrigenses y los Salmanticenses, de la misma fecha. ${ }^{49}$ En la provincia de Cáceres el de Jarandilla de la Vera, entre los ...obrigenses y Avilenses, de los años 5-6 d.C. ${ }^{50} \mathrm{Y}$ en Portugal los de Peroviseu, entre los Lancienses y los Igaeditani, del 4-5 d.C.; ${ }^{51}$ San Salvador (Castelo Branco), entre los Lancieses Oppidani y los Igaeditani, del 5-6 d.C.;2 Ul (Aveiro), entre los Turduli Veteres y los Talabrigenses: ${ }^{33}$ Guardâo (Viseu), en el que sólo puede leerse el final del nombre de la última comunidad, ...ie(n)ses, datable entre 2 a.C. y el 14 d.C. ${ }^{54}$ pero que debe de ser, como los restantes del mismo territorio, de los años 4-6 d.C. A todos ellos, datados como vemos en época de Augusto, pueden añadirse dos más: uno de Goujoim (Viseu), entre los Arabrigenses y los Coilarni, del año 43 d.C. ${ }^{55}$ y otro de San Pedro de Balsemâo (Viseu), también del 43 d.C. ${ }^{56}$

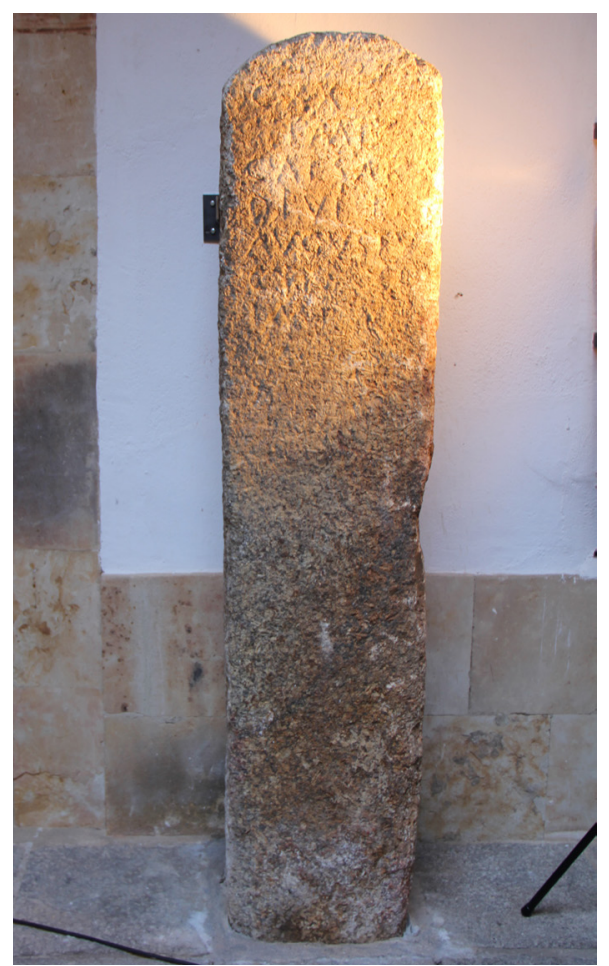

Fig. 5. Miliario augusteo de Fuenteguinaldo (Salamanca). Foto de M. Salinas y J. J. Palao.

\footnotetext{
48 CORTÉS BÁRCENA 2013, nº 8.

49 CORTÉS BÁRCENA 2013, $\mathrm{n}^{\circ} 9$.

50 CORTÉS BÁRCENA 2013, $\mathrm{n}^{\circ} 2$.

51 CORTÉS BÁRCENA 2013, n⿳05.

52 CORTÉS BÁRCENA 2013, nº.

53 CORTÉS BÁRCENA 2013, nº 10 .

54 CORTÉS BÁRCENA 2013, $\mathrm{n}^{\circ} 12$.

55 CORTÉS BÁRCENA 2013, $\mathrm{n}^{\circ} 1$.

56 CORTÉS BÁRCENA 2013, nº 13 .
} 
A esta relación debemos añadir un fragmento de inscripción de Yecla de Yeltes que probablemente corresponde también a otro terminus augustal. ${ }^{57}$ Se trata de un fragmento de arenisca con forma cuadrada cuya superficie presenta varias hendiduras resultantes, posiblemente, de afilar algún objeto metálico (navaja o instrumento agrícola). Se desconoce el lugar exacto de procedencia aunque probablemente se encontraría en las inmediaciones del castro de Yecla la Vieja. Se intuyen cuatro líneas en la inscripción, aunque sólo son legibles las dos primeras. La tercera está dañada por las mencionadas incisiones, mientras que la última parece estar cortada por la fractura de la pieza. La lectura sería: [---]/ [Miro]brige/ [n]ses/ []o[]/ [+++]o/ [---].Esta pieza presenta numerosas particularidades en el conjunto de la epigrafía de Yecla de Yeltes. En función de la presencia de lo que consideramos una origo en plural, o etnónimo, creemos que podría tratarse de un nuevo terminus territorial, similar a los documentados en Ciudad Rodrigo, Ledesma y Traguntía. En esta última aparece el término Mirobrigenses desarrollado de forma completa, tal y como creemos que es el caso de la inscripción aquí presentada. De ser cierta esta interpretación nos hallaríamos ante un nuevo ejemplo de terminus en Lusitania que debería fecharse, como el resto de los de la provincia, en los inicios del siglo I d.C.

Dentro de este contexto, es interesante también un nuevo miliario de Augusto hallado en Fuenteguinaldo (Fig. 5), en el extremo suroccidental de la provincia de Salamanca, ${ }^{58}$ cuya datación puede oscilar entre el 1 de julio del año 16 a.C., fecha del inicio de la salutación imperatoria X, y el 5 de marzo del año 6 a.C., última fecha en la que coinciden el consulado XI y la salutación imperatoria XIIII. Este miliario presenta un notable interés porque atestigua una intervención augustea muy al norte de Lusitania y muy tempranamente, en una zona donde no se conocían intervenciones viarias hasta la época de Nerón. ${ }^{59}$ Otros dos miliarios muy semejantes en su forma y en su redacción, datados por Curado en el año 23 a.C., han aparecido en Argomil y en Alfaiates, en el distrito de Guarda en Portugal ${ }^{60}$ señalando lo que podría ser una vía de penetración desde Mérida, pasando por Coria, en dirección noroeste. Desconocemos la vía a la que podría pertenecer el miliario de Fuenteguinaldo, pero, dada su situación geográfica, hay que descartar que perteneciera a la llamada "vía de la plata". Podría tratarse de una vía que, partiendo de Turmuli (Alconétar), se dirigiera al puerto de Perales por Caurium y alcanzase Ciudad Rodrigo, de la cual no quedan vestigios arqueológicos pero cuya existencia hay que suponer para unir una serie de puntos estratégicos. ${ }^{61}$ Pero también es posible suponer otra vía romana que ascendería desde Extremadura hacia la provincia de Salamanca por el Puerto de Santa Clara, desde San Martín de Trevejo hasta Fuenteguinaldo, ${ }^{62}$ precisamente, enlazando la cabecera del río Eljas con la cabecera del Águeda, junto a cuyo curso se ha encontrado el miliario.

57 Palao - Salinas 2009: [---]/ [Miro]brige/ [n]ses/ []o[]/ [+++]o/ [---]

58 Salinas - Palao 2012, 273-280: CXX/Imp(erator) Caesar Divi f(ilius)/Augustus/ co(n)sul XI/ imp(erator) $X$.

59 ROLDÁN 1971, 59 ss; 65.

60 CuRAdo 2013, quien propone leer en el miliario de Fuenteguinaldo: .../ CO(n)S(ul) XI/ IMP(erator) VIII, asignándole una cronología del año 23 a.C., igual a la de los otros dos miliarios de Alfaiates y Argomil.

61 Fernández CoRrales 1987, 85-86.

62 García de Figuerola 1999, 116-119. 
Es posible, por tanto, que el miliario de Fuenteguinaldo corresponda a una vía que se iniciaba en Emerita y se dirigía a algún punto del occidente salmantino o de los territorios vecinos de Portugal, en todos los cuales existen zonas mineras explotadas por los romanos. Hay que valorar la existencia del castro de Irueña, en cuyas inmediaciones apareció el miliario, que puede corresponder a un antiguo municipium Uruniense que, tal vez, fuera mansio de esta vía.

Además de los termini augustales y los miliarios que atestiguan la reestructuración del territorio efectuada bajo Augusto, existen varios pactos de hospitalidad y patronato que, aunque se refieren a cuestiones internas de la sociedad indígena, jurídicamente peregrina, tienen interés para conocer las transformaciones sociales que comienzan a operarse y que sólo van a adquirir todo su desarrollo a lo largo del siglo I d.C. Un mapa general de los documentos de hospitalidad conocidos, tesserae y tabulae, muestra su concentración evidente en la antigua Celtiberia, es decir, el valle del Duero oriental, valle medio del Ebro y cordillera Ibérica. ${ }^{63}$ Existen algunos ejemplares en Gallaecia, Lusitania y Bética pero su área de distribución principal coincide aproximadamente con la zona en la que se documenta la dispersión de individuos de origen celtibérico. La distribución cronológica de los pactos de hospitalidad y clientela, por otra parte, muestra una clara concentración durante la dinastía julio-claudia y otra, menor, a comienzos de la dinastía de los Antoninos; este hecho nos ha llevado a plantear la posibilidad de que estos pactos hayan servido, entre otros fines, para integrar territorial y socialmente a comunidades o individuos indígenas después de dos hechos administrativos de importancia trascendental: la reorganización provincial de Augusto y la concesión del ius Latii bajo los Flavios. ${ }^{64}$

Si exceptuamos las tesserae hospitales, que no ofrecen elementos de datación seguros y que convencionalmente se suponen de época tardorrepublicana o cesariana, de las tabulae de hospitalidad y patronato conocidas caen dentro del reinado de Augusto las siguientes: Paredes de Nava, del año 2 d.C.; ${ }^{65}$ Pedroso, del año 7 d.C.; ${ }^{66}$ Pedroso, del año 9 d.C. ${ }^{67}$ Herrera de Pisuerga, del año $14 ;{ }^{68}$ y, quizás, Paredes de Nava ${ }^{69}$ Es decir, dos pactos proceden de Paredes de Nava, dos de Pedroso y uno de Herrera de Pisuerga. La sensación que se obtiene es que durante estos años en algunas comunidades del valle del Duero ha habido una necesidad perentoria de realizar este tipo de pactos.

El primero de los documentos de Paredes de Nava por su forma se adscribe al grupo de las téseras de hospitalidad, aunque por la lengua (latín) y por la estructura del texto guarda más relación con las tabulae patronatus. La datación consular proporciona la fecha del año 2 de la Era. En ella, Acces Licirni, intercatiense, hace una tésera de hospitalidad con la civitas Palantina para sí mismo, sus hijos y para los descendientes de

\footnotetext{
63 Balbín 2006, 142.

64 Salinas 2001, 247-248; Balbín 2006, 140-141.

65 BALBín 2006, n51.

66 BALBín 2006, n46a.

67 BALBÍN 2006, n46b.

68 Balbín 2006, n53.

69 Balbín 2006, n52.
} 
Anenus hijo de Ammedus. Luego sigue una cláusula final cuya interpretación ha sido muy debatida: per magistratum Elaisicum hospitio Ammi Caecaeni (...).

El segundo de los documentos de Paredes de Nava se adscribe también por su forma al grupo de las tesserae, aunque por el contenido lo hace al de las tabulae. En él Marcus Titius Fronto, turiasonense, contrae un hospitium con el populus Intercatiensis, eodem iure eadem lege qua Intercatienses. La aparición de estos dos documentos en la localidad palentina de Paredes de Nava permite suponer con cierto fundamento que ésta es la antigua ciudad de Intercatia, citada por las fuentes como perteneciente a los vacceos. ${ }^{70}$ Tanto Intercatia como Pallantia eran en estos momentos civitates peregrinae. Sobre Turiaso, en cambio, ya que no poseemos datos que proporcionen una datación exacta, es difícil pronunciarse. Balbín ${ }^{71}$ supone que la falta de datación consular puede ser un argumento a favor de una fecha antigua, a principios del Imperio o incluso antes. En ese caso, es posible que Turiaso también fuera en estos momentos una comunidad peregrina, ya que, como hemos visto, alcanzó la municipalización bajo Tiberio. Este horizonte indígena se ve reforzado, en el caso del primer documento, por la onomástica de las personas citadas en él: Acces hijo de Licirnus, Anenus hijo de Ammedus, el magistratum Elaisicum y Ammi Caecani, que puede ser el nombre de una o de dos personas diferentes en genitivo. En el segundo caso, los tria nomina de Marcus Titius Fronto, sin mención de la filiación y de la tribu, podrían indicar que nos hallamos ante un ciudadano latino, y no romano. No obstante, la situación es más compleja ya que, si consideramos que la inscripción es de fecha muy antigua, entonces el uso del cognomen no se había generalizado, como muestra, por ejemplo, una inscripción del año 6 a.C. de Idanha-a-Velha en la que Q. Talius, emeritense de la tribu Papiria, luego ciudadano romano, no menciona su cognomen. ${ }^{72}$ Es posible, por tanto, que la inscripción no sea tan antigua como se supone, aunque hay que datarla probablemente antes del momento en que Turiaso se convirtiera en municipio, ya que dicha circunstancia no se menciona en la origo de M. Titius Fronto.

Las dos inscripciones de Pedroso se suceden con dos años de diferencia, en el 7 y el 9 de la Era. Las dos provienen de la Lusitania septentrional, no de la Citerior como se ha dicho, ya que Vila Nova de Gaia se encuentra al sur del Duero, que constituía el límite entre Lusitania y la Citerior. Incluso, algunas civitates adscritas a Lusitania se hallaban al norte del río. ${ }^{73}$ En la primera de dichas inscripciones D(ecimus) Iulius $\mathrm{D}$ (ecimi) f(ilius) Cilo, de la tribu Galeria, contrae un hospitium con tres personas: $\mathrm{Ni}$ ger, Rufus y Priscus, de los Turduli Veteres. En la segunda, D(ecimus) Iulius M(arci) f(ilius) Cilo, de la misma tribu, hace un hospitium con Lugarius Septani filius, ex Tuduleis Veteribus; actuando en el pacto el mismo Lugarius Septani. La suposición de que en ambos documentos aparece el mismo personaje y de que en uno de ellos la filiación ha sido mal dada por error del grabador nos parece menos probable que la interpretación de C. Castillo, para la cual hay dos individuos diferentes, padre e hijo, tío y sobrino o primos entre sí. Padre e hijo no pueden ser porque, si tenemos en cuen-

70 Plb., 34.9.13; Str., III 4.13; App., Ib. 53-54; Ptol., 2.6.49.

71 BALBÍN 2006, 211.

72 ILER 2082; AE 1961, 349; HEp 2, 1990, 770.

73 Alarcîo ET ALII 1990. 
ta la filiación, el pacto más antiguo se habría hecho con el hijo (Decimus... D(ecimi) $f$.), y el más reciente con el padre (Decimus... M(arci) f.), de manera que la cláusula en este último de que el hospitium se contrae sibi liberis posterisque suis resultaría redundante puesto que, al menos el primero, ya tenía contraído un pacto de este tipo. La adscripción de estas personas a la tribu Galeria podría evidenciar la promoción de algunos indígenas a la ciudadanía romana bajo el gobierno de Augusto, pero entonces habría que preguntarse cuál podría ser el interés por estrechar estos lazos de hospitalidad con una comunidad peregrina, la del castro de Monte Murado, perteneciente a los Turduli Veteres, ya que en este caso la adquisición de una ciudadanía indígena, por decirlo así, no parece haber sido un aliciente.

Finalmente, la tésera de Herrera de Pisuerga, ampliamente comentada desde su publicación por A. García y Bellido, ${ }^{74}$ registra un hospitium entre Amparamus Nemaiecanum, consaburense, y la civitas Maggaviensium representada a través de su senatus y magistratus, en función del cual se le da la civitas honoraria: todos los magavienses lo recibieron en su hospitium, fides y clientela, eademque condicione esset qua civis. Aunque se ha querido ver en Amparamus a un aristócrata indígena y, por tanto, la parte más potente en este pacto, el hecho es que son él, sus hijos y descendientes quienes entran en el hospitium y clientela de los magavienses que, no hay duda, son una comunidad peregrina ya que aparece gobernada por senatus y magistratus, como es característico de las comunidades peregrinas y no por los municipios romanos.

Dejando a un lado los motivos por los que Amparamus pudiera estar interesado en contraer este pacto, que evidentemente no se limitaban a la adquisición de la ciudadanía honoraria sino a ventajas más concretas, podemos suponer que hubo un interés por parte de ciertas personas de posición local relevante de no romper o de establecer vínculos con algunas civitates peregrinae, quizás porque la nueva organización administrativa establecida por Augusto podía romper lazos preexistentes que eran de distinta naturaleza. En este sentido nos parece muy importante que en el pacto de Herrera de Pisuerga quedasen comprendidos los liberi, libertique posterique de Amparamus, ya que la mención explícita de los libertos no es usual en este tipo de documentos (de hecho no aparecen mencionados en ninguno de los documentos de hospitalidad y clientela conocidos). Los libertos formaban parte de la familia según el derecho romano, estando asimilada su situación a la de los clientes (clinex libertinus: Liv., 43.16.4), hasta el punto de que en caso de un cambio de nombre por parte del antiguo propietario (por ejemplo, en un caso de adopción), sus libertos adquirían consecuentemente su mismo nombre. ${ }^{75}$ Es posible, por tanto, que su mención explícita tenga que ver con el deseo de no dejar fuera del pacto ningún aspecto que no pudiera encajar en él por diferencias entre el derecho romano y el derecho peregrino, que desconocemos.

En relación con la reestructuración que experimentan estos territorios durante el reinado de Augusto, puede ponerse un documento un poco posterior, el denominado

74 GARCÍA Y BELLIDO 1966.

75 DaremberG-Saglio III, 2, col. 1200: libertus, libertinus. 
bronce de El Picón, en Pino de Oro (Zamora), del año 27 d.C. ${ }^{76}$ Este epígrafe registra un tratado de fides y amicitia entre un particular, cuyo nombre se ha perdido por rotura de la pieza, y el senatus populusque Bletisamensium, comunidad que podemos identificar con la Bletisama mencionada en los Termini Augustales de veinte años antes. Es imposible saber las razones concretas que pudieron llevar a este individuo a solicitar la amicitia de los bletisamenses. Si amicitia se está usando en este documento como sinónimo de clientela, la comparación con otros documentos puede resultar esclarecedora. En la tésera de Herrera de Pisuerga, del año 14 d.C., se dice que Amparamus, al contraer el hospitium y clientela con los magavienses, adquiere los mismos derechos que un cives Maggaviesis. En una de las téseras de Paredes de Nava se dice del adquiriente que tiene eodem iure eadem lege. En la de Peralejo de los Escuderos los Dercinoasedenses, vicani Cluniensium, adquierem eodem iure y son cives Termestini. Los pactos de hospitalidad y clientela podían ser una forma de obtener la ciudadanía en otra civitas distinta de la del contrayente, de la misma manera que la relación de amicitia o clientela de algunos reyes del periodo final de la República e inicios del Imperio, llevaba aparejada consigo la concesión de la ciudadanía romana. ${ }^{77}$ En los municipios y colonias el acceso a la propiedad de la tierra pasaba por poseer el derecho de ciudadanía local, de manera que quien no era ciudadano no podía poseer tierras en la civitas. Es posible que la situación en las civitates stipendiariae como Bletisama fuera semejante y por tanto que, si un individuo ajeno a la comunidad, deseaba explotar filones mineros debiera tener previamente la ciudadanía local. Este puede haber sido el interés subyacente al documento de Pino del Oro.

Vuelvo al comienzo. Es evidente que Augusto necesitaba contar con la aristocracia local de las poblaciones del valle del Duero, que era la única clase que le podía garantizar el suministro de víveres y auxiliares para el ejército durante la guerra contra los cántabros y astures, y que dicho apoyo contaba con algún tipo de recompensa por parte del emperador. El recurso de los romanos a miembros de la aristocracia indígena durante las guerras de conquista está atestiguado en las fuentes literarias. Es el caso de la guerra contra Viriato, durante la cual un tal Gayo Marcio de Itálica, que era del país, se hizo cargo de la guerra mientras el cónsul invernaba ${ }^{78}$ Durante la guerra de Sertorio los pueblos del valle del Duero, y por tanto sus aristocracias, tomaron partido por los contendientes, principalmente por Sertorio contra Metelo y Pompeyo. La abundancia del nomen Iulius en Lusitania generalmente se ha interpretado como una consecuencia de la concesión de ciudadanía por parte de César o de Augusto a indígenas a los que recompensarían por su fidelidad.

76 Sastre - Beltrán 2010. Primer fragmento: [M $\cdot$ Licinio $\cdot$ Cr]asso $\cdot$ Fr $[$ ugi $\cdot$ et] $/[$ L $\cdot$ Calpurnio $\cdot$ Pisone $\cdot$ cos] (año 27 d.C.). Segundo fragmento: [... hospitium ... reno]/vavit · cum s[enatu popul]/oq(ue) Bletisam[ensi ... Eum]/que senatus [populusque] / Bletisamen[sis liber]/os · posterosq(u)e · ei[us...in... am]/ icitiamque su[am receperunt]/ ita $\cdot$ ut civem $[\ldots] /$ in perpetu[o ... ]/ egit ipse $A[\ldots] /$ T O N E [...]

77 SALinas 2010.

78 App., Ib. 66: “...y, con frecuencia, (Quintio) enviaba contra él a Gayo Marcio, un ibero de la ciudad de Itálica”. 


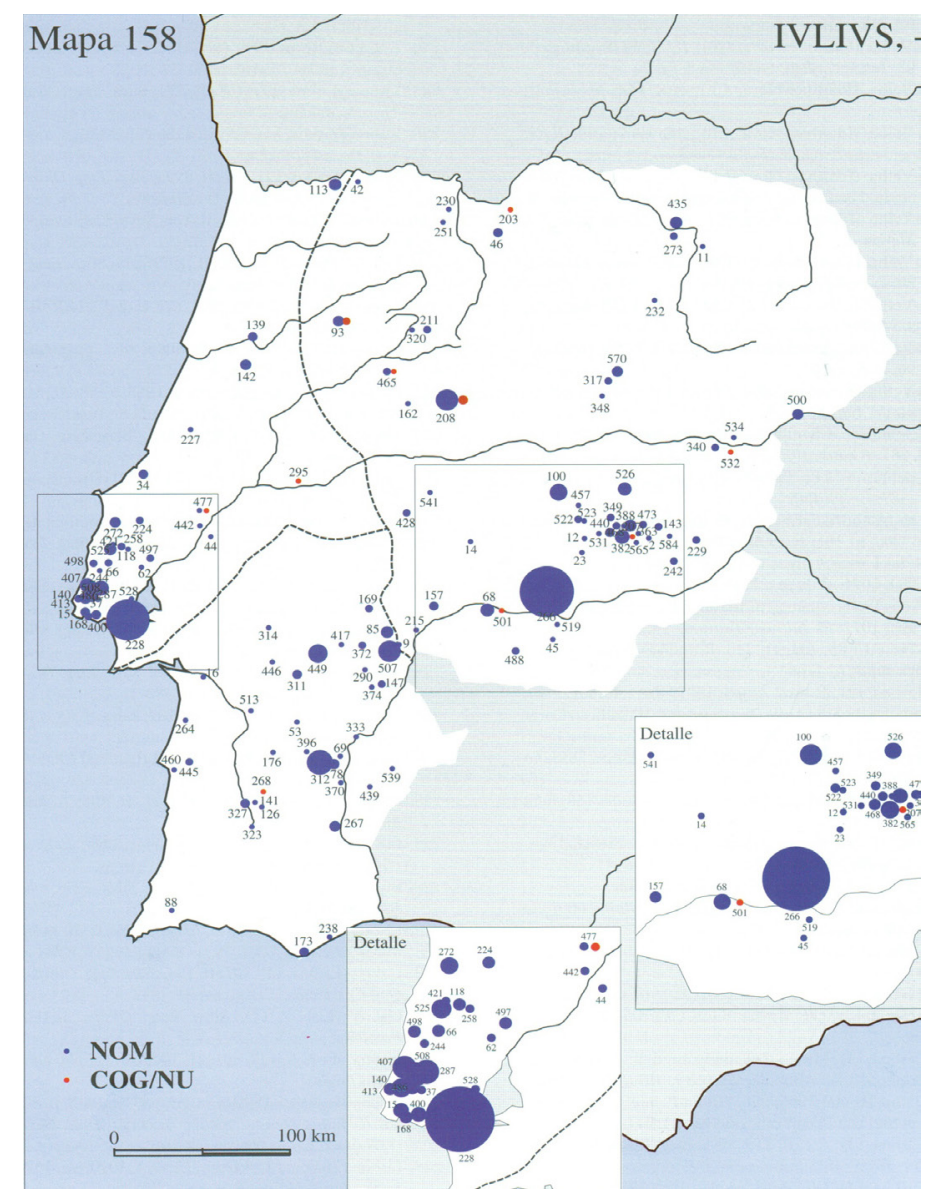

Fig. 6. Distribución del nomen Iulius en Lusitania, según Navarro Caballero - Ramírez Sádaba 2003.

La distribución del nomen Iulius en la provincia Lusitania (Fig. 6) muestra dos grandes concentraciones: ${ }^{79}$ una en torno a Augusta Emerita, colonia fundada por Augusto, y otra en torno a Olisipo, promocionada a municipio de ciudadanos romanos por él. Otra concentración menor discurre a lo largo del curso inferior del Guadiana, principalmente en torno a Pax Iulia, colonia también de fundación augustea. Al norte del Tajo la frecuencia de Iulii es menor, pero hay una cierta concentración en la civitas Igaeditanorum, donde se atestigua una romanización precoz ya en época del primer emperador, y luego hallamos pequeñas concentraciones en Salmantica, Almofala, Cárquere y otros lugares. Esta zona geográfica coincide con la zona septentrional de Lusitania donde se hallan los termini que atestiguan una reorganización

79 NAVARro - RAMÍREZ SÁDABA 2003, 197-204, s.v. Iullius. 
del territorio bajo Augusto. Es difícil por tanto no ver una relación entre un hecho y otro, aunque la relación exacta no aparezca muy claramente. En Salmantica se atestigua una familia importante de Iulii que poseían varios libertos que se documentan en época flavia, probablemente. Creemos que en estos Iulii hay que ver descendientes de aristócratas locales que adquirieron la ciudadanía, probablemente de manera viritana, bajo Augusto. ${ }^{80}$ Los propios libertos debían de ser relativamente ricos y estar lo suficiente aculturados desde el punto de vista romano como para dejarnos sus epígrafes. Por tanto, sus antiguos dueños pueden ser calificados de modestos aristócratas, a escala local. Es poco probable que la adquisición del nomen Iulius se hiciera bajo el gobierno de César, ya que su estancia como pretor en la provincia fue fugaz, pues ni agotó siquiera el año de mandato, y dejó mal recuerdo en la provincia. En cambio, la aristocracia local pudo prestar buenos servicios al emperador en la retaguardia del frente contra los astures.

El impacto específico de la romanización en la cuenca del Duero durante el reinado de Augusto es algo que todavía resulta difícil de determinar, tal vez por la escasez de datos todavía disponibles, por la imposibilidad a veces de atribuir algunos de ellos (especialmente los datos arqueológicos) de manera unívoca al reinado del emperador, y tal vez, también, por la inexistencia de un modelo teórico, que no sea el simple modelo positivista o historicista, que permita abordar de manera más eficiente esta cuestión. Evidentemente, para valorar dicho "impacto" hay que partir de las realidades indígenas previas a la conquista romana y compararlas con lo que posteriormente nos aparece a partir de comienzos del Imperio romano. Dichas realidades no son homogéneas en el conjunto de la cuenca. Desde el punto de vista arqueológico, se ha señalado la existencia de áreas culturales diferentes que evolucionan con relativa independencia unas de otras durante la II Edad del Hierro. ${ }^{81}$ Así, además de un área celtibérica estrictamente dicha que aparece como la zona más dinámica, desde la que se difunden novedades hacia Occidente en el campo del armamento, la cerámica o las técnicas constructivas ${ }^{82}$, se distingue una zona central caracterizada por la importancia del substrato de la cultura de Soto de Medinilla y unas zonas aparentemente "periféricas" con una fuerte influencia de la cultura castreña, representadas por los vettones en el suroeste de la cuenca y los castros astures del noroeste de la misma. Todas estas zonas, aunque diversas desde el punto de vista de la cultura material, sin embargo, comparten un mismo fenómeno social de creación de grandes oppida donde se produce una concentración de la población, una especialización de la producción artesanal y la aparición de una aristocracia que demanda bienes de consumo suntuarios de origen exótico. Son estos oppida los que van a aparecer como las principales poleis antagonistas de los romanos en un proceso de conquista que culmina, precisamente, con Augusto.

La valoración adecuada de la política augustea en el valle del Duero debe tener en cuenta también el pasado republicano de la región, que no fue homogéneo ni contempló los mismos fenómenos en toda ella. La conquista romana supuso una re-

80 SAlinas $1992,305$.

81 Delibes et aliI 1995; para los astures: Esparza 1986; Celis et aliI 2002, 268-270.

82 Martín VAlls - EsParza 1992. 
organización del territorio a finales del siglo II a.C., por lo menos en la parte oriental, ya que sabemos que Escipión después de conquistar Numancia repartió su territorio entre los pueblos vecinos, premiando a aquellos que apoyaron a los romanos e imponiendo multas a quienes se hicieron sospechosos. ${ }^{83}$ Podría compararse esta política de Escipión con la expresada en el decreto de El Bierzo, de Augusto, por el que éste concedía la inmunidad a los castellani Paemeiobrigenses y transfería sus munera a los castellani Aliobrigiaecini. No sabemos hasta qué punto medidas como las tomadas en Numancia afectaron también a otras ciudades que se enfrentaron a los romanos, pero el hecho de que Apiano diga que la comisión decenviral organizó los territorios conquistados por Escipión y Décimo Bruto ${ }^{84}$ invita a pensar que algún tipo de organización territorial afectó no sólo al valle del Duero oriental, Celtiberia, sino también a la zona más occidental.

Durante la guerra sertoriana las ciudades de Celtiberia jugaron un papel militar muy importante apoyando a Sertorio contra Pompeyo. En cambio, si se exceptúa Cale, que aparece en un fragmento de ubicación cronológica incierta, las ciudades del Duero occidental no parecen haber tenido una importancia militar tan grande, aunque la existencia de tesorillos de esta época en la zona occidental atestigua que la inestabilidad se extendió también a esta región..$^{85}$

El resultado de la conquista romana fue diverso. En unos casos, como en Numancia, supuso la destrucción de la ciudad, que sólo se recuperó después de un intermedio mal conocido, y que en todo caso perdió su liderazgo dentro de los arévacos en beneficio de otros núcleos, como Tiermes, Clunia o Uxama, que acceden a la municipalidad a partir, no de Augusto, sino de Tiberio. En otros casos, como en el oppidum de Salmantica, se produce una evolución paulatina hacia formas de vida romana que sólo parece apreciable a partir de época de Claudio y que estaría en la base de la transformación de la ciudad en municipio, probablemente, en época de Vespasiano, ${ }^{86}$ lo mismo que la mayoría de las ciudades de la cuenca del Duero. En otros casos, en fin, como el de Lancia, que tiene indudable interés por haber sido, como señalábamos al principio, la principal ciudad resistente de los astures, las recientes excavaciones arqueológicas muestran la continuidad del hábitat entre la II Edad del Hierro y la época imperial, coincidiendo con la noticia de las fuentes literarias de que Carisio no quiso destruirla para que sirviera de monumento a su victoria, no sin que entre una época y otra no se produjese una profunda remodelación del urbanismo que ha borrado gran parte de las huellas de la ciudad indígena. ${ }^{87}$

En este contexto heterogéneo, por tanto, el valle del Duero fue principalmente una zona de ocupación militar, especialmente al norte del río, con la permanencia de tres legiones desde el final de las guerras hasta la muerte del emperador. Algunas ciudades arévacas, tal vez por su mayor relación con el valle del Ebro, debieron de experimentar un desarrollo económico y social que explicaría su conversión en mu-

\footnotetext{
83 App., Ib. 98.

84 App., Ib. 99.

85 Salust., Hist. 3.43; Blázquez Cerrato 2002, 176.

86 SALINAS 2008.

87 Floro, 2.33.57-58; Celis ET ALII 2002.
} 
nicipios a partir de la época de Tiberio; pero el resto de las ciudades, quizás menos dinámicas o menos ricas, tuvieron que esperar a finales del siglo I d.C. para dar este paso en el contexto, ya, de la municipalización flavia. Sin embargo, durante el reinado de Augusto se procedió a definir la trama urbana, mediante de delimitación de los fines entre las civitates, y a trazar las infraestructuras, principalmente vías de acceso a las regiones mineras, que sentarían las bases de la romanización a largo plazo del territorio.

\section{BibLIOgRAFía}

Aвásolo, J. A. (2007): "Lara de los Infantes, municipium a pesar de la arqueología", [en] M. Navarro Caballero - J. J. Palao Vicente (eds.), Villes et territoires dans le bassin du Douro à l'èpoque romaine, Bordeaux, 125-148.

AlarcÂO, J. ET ALII (1990): "Propositions pour un Nouveau tracé des limites anciennes de la Lusitanie romaine", [en] Les villes de Lusitanie romaine. Hiérarchies et territoires, Paris, 319-328.

Alfaro, C. et ALII (1997): Historia monetaria de la Hispania antigua, Madrid.

AlföLdi, G. (2001): "El nuevo edicto de Augusto de El Bierzo en Hispania", [en] L. Grau - J. L. Hoyas (eds.), El bronce de Bembibre. Un edicto del emperador Augusto, Valladolid, 17-27.

ArCE, L. (1982): El último siglo de la España romana: 284-409, Madrid.

ARIÑo GIL, E. (2005): "El ager per extremitatem mensura comprehensus", [en]: L'Aquitaine et l'Hispanie septentrionale à l'époque Julio-Claudienne. Organisation et exploitation des espaces provinciaux. IV Colloque Aquitanie, (Saintes, septembre 2003), (=Aquitania Supplément 13), Bordeaux.

ARIÑO, E. ET ALII (2007): “Albocela (Villalazán, Zamora): interpretación de la ciudad romana a partir de la fotografía aérea y de la prospección intensiva", [en] M. Navarro Caballero - J. J. Palao Vicente (eds.), Villes et territoires dans le bassin du Douro à l'èpoque romaine, Bordeaux, 171-194.

Balbín, P. (2006): Hospitalidad y patronato en la península Ibérica durante la Antigüedad, Salamanca.

Barbero, A. - Vigil, M. (1974): Sobre los orígenes sociales de la Reconquista, Barcelona.

BARRANDON, N. (2011): De la pacification à l'integration des hispaniques (133-27 a.C.): les mutations des societés indigènes d'Hispanie centrale et septentrionale sous la domination romaine, Paris.

Blázquez Cerrato, C. (2002): Circulación monetaria en el área occidental de la península Ibérica: la moneda en torno al "camino de la Plata", Montagnac.

CAVAdA, M. - Villanueva, M. (2001): "El Edicto de Bembibre y las reformas administrativas de Augusto en el Noroeste", [en] L. Grau - J. L. Hoyas (eds.), El bronce de Bembibre. Un edicto del emperador Augusto, Valladolid, 129-134.

CELIS SÁNCHEZ, J. ET ALII (2002): "Nuevos datos y aportaciones a la ciudad de Lancia (Villasabriego, León, España)", Zephyrus 55, 257-282.

Cortés BÁRCENA, C. (2013): Epigrafía en los confines de las ciudades romanas. Los Termini publici en Hispania, Mauretania y Numidia, Roma. 
Costabile, F. - Nicandro, O. (2000): Tessera Paemeiobrigensis. Un nuovo editto di Augusto dalla Transduriana provincia è l'imperium proconsulare del princeps, Roma.

Cruz Andreotti, G. et ALII (eds.) (2007): La invención de una geografía de la península Ibérica, II. La época imperial, Madrid-Málaga.

Curado, F. P. (2013): "Notas sobre dois miliários prismáticos, de Augusto (23 a.C.), da regiâo da Guarda", Sabucale 5, 59-74.

CURCHIN, L.

(2004): The romanization of central Spain. Complexity, Diversity and Change in a Provincial Hinterland, New York.

(2007): “L'administration romaine dans la vallée du Douro", [en] M. Navarro Caballero - J. J. Palao Vicente (eds.), Villes et territoires dans le bassin du Douro à l'èpoque romaine, Bordeaux, 91-96.

Delibes de Castro, G. et alit (eds.) (1995): Arqueología y medio ambiente. El primer milenio a.C. en el Duero medio, Valladolid.

Esparza Arroyo, A. (1986): Los castros de la Edad del Hierro del Noroeste de Zamora, Zamora.

FERNÁNDEZ CORRALES, J. M. (1987): El trazado de las vías romanas en Extremadura, Cáceres.

García de Figuerola, M. (1999): Arqueología romana y altomedieval de la sierra de Gata (El valle de Valverde, provincia de Cáceres), Cáceres.

GARCÍA y Bellido, A. (1966): “Tessera hospitalis del año 14 de la era hallada en Herrera de Pisuerga", BRAH 159, 149-166.

Gómez M. - Morillo, A. (2008): "Moneda romana y establecimientos militares durante las guerras cántabras y el siglo I d.C.: el registro estratigráfico de Herrera de Pisuerga (Palencia)", [en] F. Cadiou et alii (eds.), La guerre et ses traces Dans la péninsule Ibérique à l'époque de la conquête romaine: approches méthodologiques, Zaragoza-Bordeaux, 139-152.

GorrochateguI, J. ET ALII (2007): "Reflexiones sobre la historia social del valle del Duero: las denominaciones personales", [en] M. Navarro Caballero - J. J. Palao Vicente (eds.), Villes et territoires dans le bassin du Douro à l'èpoque romaine, Bordeaux, 287-340.

Grau, L. - Hoyas, J. L. (eds.) (2001): El bronce de Bembibre. Un edicto del emperador Augusto, Valladolid.

Hernández Domínguez, I. (2007): "Salmantica en época imperial. Un estado de la cuestión”, [en] M. Navarro Caballero - J. J. Palao Vicente (eds.), Villes et territoires dans le bassin du Douro à l'èpoque romaine, Bordeaux, 195-202.

KANDLER, M. (1989): Der römische limes in Osterreich: ein führer, Wien.

Liz Guiral, J. - Celis SÁnChez, J. (2007): "Topografía antigua de la ciudad de Lancia (Villasabriego, León, España)", Zephyrus 60, 241-263.

LóPez-BarJa DE Quiroga, P. (2010): “Provincia y restituo en el bronce de El Bierzo", AEA $83,175-181$.

Martín, F. (2008): "Sobre el significado de provincia", [en] C. Alonso del Real (ed.), Urbs Aeterna. Actas y colaboraciones del coloquio internacional Roma entre la literatura y la Historia. Homenaje a la profesora Carmen Castillo, Pamplona.

Martín Hernández, E. (2007): "El ejército romano en España: Bibliografía", [en] A. Morillo (ed.), El ejército romano en Hispania. Guía arqueológica, León, 413-479. 
Le Roux, P. (2007): “Las inscripciones militares", [en] A. Morillo (ed.), El ejército romano en Hispania. Guía arqueológica, León, 481-501.

Martín Valls, R. - Esparza Arroyo, A. (1992): “Génesis y evolución de la cultura celtibérica”, [en] M. Almagro - G. Ruiz Zapatero (eds.), Paletnología de la península Ibérica, (=Complutum 2.3), Madrid, 259-279.

Morillo Cerdán, A.

(2007a): "El ejército romano en España", [en] A. Morillo (ed.), El ejército romano en Hispania. Guía arqueológica, León, 87-112.

(2007b): "Los campamentos romanos de Astorga y León", [en] M. Navarro Caballero - J. J. Palao Vicente (eds.), Villes et territoires dans le bassin du Douro à l'èpoque romaine, Bordeaux, 59-90.

(2008): "Criterios arqueológicos de identificación de los campamentos romanos en Hispania", [en] F. Cadiou et alii (eds.), La guerre et ses traces Dans la péninsule Ibérique à l'époque de la conquête romaine: approches méthodologiques, Zaragoza-Bordeaux, 73-94.

Morillo Cerdán, A. ET ALII (2008): "Las guerras cántabras", [en] Aja Sánchez et alii (eds.), Los cántabros en la Antigüedad. La Historia frente al Mito, Santander, 101-132.

Navarro Caballero, M. - Ramírez SÁdaba, J. L. (coords.) (2003): Atlas antroponímico de la Lusitania romana, Mérida-Bordeaux.

Navarro Caballero, M. - Palao Vicente, J. J. (eds.) (2007): Villes et territoires dans le bassin du Douro à l'èpoque romaine, Bordeaux.

Nicolet, C. (1988): L'inventaire du monde: géographie et politique aux origines de l'empire Romain, Paris.

NúÑEZ HeRnándeZ, S. I. (2007): “Arquitectura y urbanismo en las ciudades romanas del valle del Duero: los grandes conjuntos monumentales", [en] M. Navarro Caballero - J. J. Palao Vicente (eds.), Villes et territoires dans le bassin du Douro à l'èpoque romaine, Bordeaux, 99-124.

NúÑez Hernández, S. - Curchin, L. A. (2007): “Corpus des villes”, [en] M. Navarro Caballero - J. J. Palao Vicente (eds.), Villes et territoires dans le bassin du Douro à l'èpoque romaine, Bordeaux, 432-612.

OCÁRIz GIL, P. (2009): “Organización administrativa y territorial de las provincias hispanas durante el Alto Imperio", [en] J. Andreu et alii (eds.), Hispaniae. Las provincias hispanas en el mundo romano, Tarragona, 323-338.

Palao Vicente, J. J. (2007): "Epigrafía y sociedad en la provincia de Salamanca durante el Alto Imperio", [en] M. Navarro Caballero - J. J. Palao Vicente (eds.), Villes et territoires dans le bassin du Douro à l'èpoque romaine, Bordeaux, 239-268.

Palao Vicente, J. J. - Salinas, M. (2009): "Nuevas inscripciones latinas del castro de Yecla de Yeltes (Salamanca)", Habis 40, 171-196.

Prontera, F. (1990): Geografia e geografi nel mondo antico: guida storica e critica, Roma.

Rabanal Alonso, M. A. - García Martínez, S. (2001): Epigrafía romana de la provincia de León, León.

REDDÉ, M. "Les Camps militaires républicains et augustéens: paradigmes et réalités archéologiques", [en] F. Cadiou et alii (eds.), La guerre et ses traces dans la péninsule Ibérique à l'époque de la conquête romaine: approches méthodologiques, Zaragoza-Bordeaux, 61-72. Roddaz, J. M. (2007): “Le Douro: ligne de frontiere ou lieu de contact?”, [en] M. Nava- 
rro Caballero - J. J. Palao Vicente (eds.), Villes et territoires dans le bassin du Douro à l'èpoque romaine, Bordeaux, 15-25.

Roldán Hervás, J. M. (1971): Iter ab Emerita Asturicam. El camino de la plata, Salamanca.

SALINAS DE FRÍAS, M.

(1992): "El elemento romano de Salamanca durante el Alto Imperio", [en] Actas del I congreso de Historia de Salamanca (1989), Tomo I, Salamanca, 301-310.

(1994): "Unidades organizativas indígenas y administración romana en el valle del Duero", [en] M. C. González - J. Santos (eds.), Las estructuras sociales indígenas del norte de la península Ibérica, Vitoria, 167-180.

(1998): "La guerra de los cántabros y astures, la etnografía de España y la propaganda de Augusto", [en] M. J. Hidalgo et alii (eds.), Romanización y reconquista en la península ibérica: nuevas perspectivas, Salamanca, 155-170.

(2001a): "Fides, hospitium y clientela en Hispania", [en] F. Villar - Mª P. Fernández Álvarez (eds.), Religión, lengua y cultura prerromanas de Hispania, Salamanca, 241-255.

(2001b): "Dión Casio, la Transduriana provincia y la evolución del ordenamiento augústeo de Hispania", [en] L. Grau - J. L. Hoyas (2001): El bronce de Bembibre. Un edicto del emperador Augusto, Valladolid, 135-142.

(2008): "Problemas de ordenación territorial y social de Salamanca en la Antigüedad", [en] J. Mangas - M. A. Novillo, El territorio de las ciudades romanas, Madrid, 333-358.

(2010): "Fides amicitiae Bletisamensium", [en] I. Sastre - A. Beltrán (eds.), El bronce de El Picón (Pino de Oro). Procesos de cambio en el occidente de Hispania, Valladolid, 137-144.

SAlinas de Frías, M. - Rodríguez Cortés, J. (2007): "El culto imperial en el contexto político y religioso del conventus Emeritensis", [en] T. Nogales - J. González (eds.), El culto imperial. Politica y poder, Roma, 159-178.

Salinas de Frías, M. - Palao Vicente, J. J. (2012): "Nuevo miliario de Augusto procedente de Fuenteguinaldo (Salamanca)", AEA 85, 273-280.

Sánchez Palencia, F. J. - Mangas, J. (eds.) (2000): El edicto de El Bierzo. Augusto y el noroeste de Hispania, Ponferrada.

SÁnchez PAlencia, F. J. et ALII (2001): "La primera ocupación romana de Asturia: el edicto de El Bierzo y su contexto arqueológico", [en] L. Grau - J. L. Hoyas (eds.), El bronce de Bembibre. Un edicto del emperador Augusto, Valladolid, 97-110.

Santos Yanguas, J. et aliI (2005): Epigrafía romana de Segovia y su provincia, Segovia.

SASTRE Prats, I.

(2001): Las formaciones sociales rurales de la Asturia romana, Madrid.

(2002): Onomástica y relaciones politicas en la epigrafía del conventus Asturum durante el alto Imperio, Madrid.

Sastre, I. - Beltrán, A. (eds.) (2010): El bronce de El Picón (Pino de Oro). Procesos de cambio en el occidente de Hispania, Valladolid.

TraInA, G. (2007): 'La géographie entre érudition et politique: Pline l'Ancien et les frontières de la connaisence du monde", [en] Cruz Andreotti et alii (eds.), La invención de una geografía de la península Ibérica, II. La época imperial, Madrid-Málaga, 95-114.

Villaronga, L. (1979): Numismática antigua de Hispania, Barcelona.

VV.AA. (2007): “Asentamientos militares de época romana en Hispania: una guía arqueológica”, [en] A. Morillo (ed.), El ejército romano en Hispania. Guía arqueológica, León, 223-412. 